\title{
Correction to: Comparison of outcomes after topography-modified refraction versus wavefront-optimized versus manifest topography-guided LASIK
}

\author{
Jaeryung Kim ${ }^{1+}$, Sung-Ho Choi ${ }^{2+}$, Dong Hui Lim', Gil-Joong Yoon ${ }^{2^{*}}$ and Tae-Young Chung ${ }^{1 *}$
}

\author{
Correction to: BMC Ophthalmol (2020) 20:192 \\ https://doi.org/10.1186/s12886-020-01459-0
}

Following publication of the original article [1], we were notified that the paper confirmed a previous study by Wallerstein et al. [2] and that this study was not cited in the published manuscript. The citation is included below.

Original:

- Our results showed that the predictability of the refractive correction and visual outcomes did not differ significantly among WFO-, manifest TG-, and TMR-LASIK, similar with those of previous contralateral-eye comparisons of WFO-LASIK with manifest TG- or TMR-LASIK [3-5]. However, in this study, the mean value of postoperative RA was higher in TMR-LASIK, and TMR-LASIK showed a significantly-skewed distribution of postoperative RA toward higher astigmatic values than WFO- and manifest TGLASIK. On the other hand, a previous comparison between WFO- and TMR-LASIK reported conflicting results with respect to RA [5].
Corrected:

- Our results showed that the predictability of the refractive correction and visual outcomes did not differ significantly among WFO-, manifest TG-, and TMR-LASIK, similar with those of previous contralateral-eye comparisons of WFO-LASIK with manifest TG- or TMR-LASIK [3-5]. However, in this study, the mean value of postoperative RA was higher in TMR-LASIK, and TMR-LASIK showed a significantly-skewed distribution of postoperative RA toward higher astigmatic values than WFO- and manifest TG-LASIK. Similar results were previously reported by Wallerstein et al. [2] who found that in cases of eyes having a RA versus CA axis difference higher than $20^{\circ}$, eyes treated with TMR-LASIK had higher postoperative RA compared to those treated with manifest TG-LASIK. On the other hand, a previous comparison between manifest TG- and TMRLASIK reported conflicting results with respect to postoperative RA [5].

* Correspondence: yoonalpha@gmail.com; tychung@skku.edu

† Jaeryung Kim and Sung-Ho Choi contributed equally to this work.

${ }^{2}$ BALGEUN-EYE21 Operation Center, Gwangju, Republic of Korea

'Department of Ophthalmology, Samsung Medical Center, Sungkyunkwan

University School of Medicine, Seoul, Republic of Korea

(c) The Author(s). 2020 Open Access This article is licensed under a Creative Commons Attribution 4.0 International License, which permits use, sharing, adaptation, distribution and reproduction in any medium or format, as long as you give appropriate credit to the original author(s) and the source, provide a link to the Creative Commons licence, and indicate if changes were made. The images or other third party material in this article are included in the article's Creative Commons licence, unless indicated otherwise in a credit line to the material. If material is not included in the article's Creative Commons licence and your intended use is not permitted by statutory regulation or exceeds the permitted use, you will need to obtain permission directly from the copyright holder. To view a copy of this licence, visit http://creativecommons.org/licenses/by/4.0/ The Creative Commons Public Domain Dedication waiver (http://creativecommons.org/publicdomain/zero/1.0/) applies to the data made available in this article, unless otherwise stated in a credit line to the data. 
Published online: 29 December 2020

\section{References}

1. Kim J, et al. Comparison of outcomes after topography-modified refraction versus wavefront-optimized versus manifest topography-guided LASIK. BMC Ophthalmol. 2020;20:192. https://doi.org/10.1186/s12886-020-01459-0.

2. Wallerstein A, Gauvin M, Qi SR, Bashour M, Cohen M. Primary TopographyGuided LASIK: Treating manifest refractive astigmatism versus Topographymeasured anterior corneal astigmatism. J Refract Surg. 2019;35:15-23.

3. Jain AK, Malhotra C, Pasari A, Kumar P, Moshirfar M. Outcomes of topography-guided versus wavefront-optimized laser in situ keratomileusis for myopia in virgin eyes. J Cataract Refract Surg. 2016;42:1302-11.

4. Kim J, Choi SH, Lim DH, Yang CM, Yoon GJ, Chung TY. Topography-guided versus wavefront-optimized laser in situ keratomileusis for myopia: surgical outcomes. J Cataract Refract Surg. 2019;45:959-65.

5. Kanellopoulos AJ. Topography-modified refraction (TMR): adjustment of treated cylinder amount and axis to the topography versus standard clinical refraction in myopic topography-guided LASIK. Clin Ophthalmol. 2016;10: 2213-21. 